\title{
A Study on the Relationship among Self-Direction Learning, Major Satisfaction and Problem-Solving Ability in Nursing Students
}

\author{
Seunghee Han \\ Dept. of Nursing Science, Gwangju University, 277 Hyduk-Ro, Nam Gu, Gwangju, \\ 61743, Korea \\ shhanj@Gwangju.ac.kr
}

\begin{abstract}
The purpose of this study was to investigate the self-directed learning, major satisfaction, problem solving ability on nursing students. The study included 213 students two university in Gwangju. In terms of correlations, there was found to be a significant positive correlation between self-directed learning and major satisfaction $(r=.408, p<.001)$ and self-directed learning and problem solving ability $(r=.7 .34, p<.001)$ and major satisfaction and problem solving ability $(r=.485, p<.001)$. On basis of these results, in order to nursing students, it is necessary to develop problem solving ability, self-direction learning, major satisfaction improvement program in extracurricular courses.
\end{abstract}

Keywords: Self-Directed, Learning, Satisfaction, Problem-solving, Nursing

\section{Introduction}

Nursing students, compared with other general university students, are required to possess professional knowledge and expertise in clinical skills [1]. When one becomes a professional nurse, one has to be in charge of the various, complicated problems of the patient under the nurse's care [2]. Problem-solving ability is an ability which overcomes challenges and makes use of all opportunities to reach a target goal [3]. Nursing students commonly experience extreme helplessness and frustration whenever they face situations where their patients' needs were not well-satisfied or if their problems were not properly solved [4]. However, the risk could be decreased if the understanding of the problem-solving ability is reinforced during clinical practices [4]. In order for this to happen, self-directed learning is being emphasized, where nursing students have to take the initiative in selecting and taking into action [5] their own learning styles and developing the ability to voluntarily monitor their own learning practice in a setting where they face various and changing situations [6]. Major satisfaction becomes a motive for acquiring necessary knowledge or skill through learning and takes an important part on the student's next stage of education and job finding [7]. Hence this study focuses on understanding the relationship and the influential factors of self-directed learning, major satisfaction, and problem solving ability in nursing students that was not covered by the existing study, and applying them as base data in developing a nursing intervention program.

\section{Method}

\subsection{Study design}

Article history:

Received (June 30, 2016), Review Result (August 03, 2016), Accepted (September 15, 2016)

Print ISSN: 2207-3981, eISSN: 2207-3159 IJANER

Copyright (c) 2016 GV Press 
This correlation study was designed to identify the degree of and relations between selfdirected learning, major satisfaction, problem solving ability of nursing students.

\subsection{Sampling and data collection}

Questionnaires were answered by sophomores majoring in nursing at a four-year university in city G from May 1 to 30, 2016. A total of 220 copies were collected and 213used for the final analysis. The seven copies that did not contain any content or too vague to understand were excluded.

\subsection{Instruments}

\subsubsection{Self-directed learning}

The questionnaire, which was developed by Lee et al. [8], had 45questions. Internal consistency (Cronbach's $\alpha$ ) that represented the reliability upon developing the instrument was 0.76 ; however, it was 0.90 in this study.

\subsubsection{Major satisfaction}

The questionnaire, which was developed by Braskamp et al. [9] and used by Kim et al. [10] had 18 questions. Internal consistency (Cronbach's $\alpha$ ) that represented the reliability upon developing the instrument was 0.92 ; however, it was 0.96 in this study.

\subsubsection{Problem solving ability}

The questionnaire, which was developed by Lee et al. [11] had 18 questions. Internal consistency (Cronbach's $\alpha$ ) that represented the reliability upon developing the instrument was 0.69 ; however, it was 0.94 in this study.

\subsection{Data analysis}

Using SPSS/Win 20.0 PC+, the relations between self-directed learning, major satisfaction and problem solving ability were analyzed by applying Pearson's correlation coefficients. The differences of self-directed learning, major satisfaction and problem solving ability based on demographic characteristics were analyzed by means of t-test and one-way ANOVA.

\section{Results}

\subsection{General characteristics of the participants}

In terms of the gender of the subjects, the majority were female, which consisted of 191 female subjects with the mean age of above 20 years old, and 176 subjects with no religious affiliation. With regard to academic achievement, 138 subjects with the mean 3.0-3.9, and 143 subjects were usually with their department satisfaction, and 118 subjects were usually with their interpersonal relationship, and 98 subjects were good with their health state. 
Table 1. General characteristics of subjects $(\mathrm{N}=213)$

\begin{tabular}{|c|c|c|c|}
\hline Characteristic & Categories & $\mathrm{N}$ & $\%$ \\
\hline \multirow{2}{*}{ Gender } & Male & 22 & 10.3 \\
\hline & Female & 191 & 89.7 \\
\hline \multirow{2}{*}{ Age } & $20>$ & 176 & 82.6 \\
\hline & $20<$ & 37 & 17.4 \\
\hline \multirow{2}{*}{ Religion } & Yes & 90 & 42.3 \\
\hline & No & 123 & 57.7 \\
\hline \multirow{3}{*}{ Academic achievement } & $2.0 \sim 2.9$ & 39 & 18.3 \\
\hline & $3.0 \sim 3.9$ & 138 & 64.8 \\
\hline & $4.0 \leq$ & 36 & 16.9 \\
\hline \multirow{3}{*}{ Department satisfaction } & Good & 59 & 27.7 \\
\hline & usually & 143 & 67.1 \\
\hline & $\mathrm{Bad}$ & 11 & 5.2 \\
\hline \multirow{3}{*}{ Interpersonal relationship } & Good & 93 & 43.7 \\
\hline & usually & 118 & 55.4 \\
\hline & $\mathrm{Bad}$ & 2 & 0.9 \\
\hline \multirow{3}{*}{ Health state } & Good & 98 & 46.0 \\
\hline & usually & 99 & 46.5 \\
\hline & $\mathrm{Bad}$ & 16 & 7.5 \\
\hline
\end{tabular}

\subsection{Degree of self-directed learning, major satisfaction and problem solving ability}

On average, the nursing students scored $3.22 \pm 0.33$ points in self-directed learning, and $3.88 \pm 0.64$ points in major satisfaction, and $3.35 \pm 0.37$ points in problem solving ability.

\subsection{Differences in self-directed learning, major satisfaction and problem solving ability based on general characteristics}

Self-directed learning according to the general characteristics of the subjects showed statistically significant difference in religion $(\mathrm{t}=2.38, \mathrm{p}<0.001)$, department satisfaction $(\mathrm{F}=20.8, \mathrm{p}<0.001)$, interpersonal relationship $(\mathrm{F}=4.78, \mathrm{p}<0.01)$, and health status $(\mathrm{F}=7.21$, $\mathrm{p}<0.01)$.

Major satisfaction according to the general characteristics of the subjects showed statistically significant difference in academic achievement $(\mathrm{F}=3.48, \mathrm{p}<0.05)$, department satisfaction $(\mathrm{F}=10.2, \mathrm{p}<0.001)$, interpersonal relationship $(\mathrm{F}=3.92, \mathrm{p}<0.05)$. 
Problem solving ability according to the general characteristics of the subjects showed statistically significant difference in religion $(\mathrm{t}=20.9 . \mathrm{p}<0.01)$, academic achievement $(\mathrm{F}=3.37$ $\mathrm{p}<0.05)$, department satisfaction $(\mathrm{F}=21.6, \mathrm{p}<0.001)$, interpersonal relationship $(\mathrm{F}=8.65$ $\mathrm{p}<0.001)$, health state $(\mathrm{F}=7.90, \mathrm{p}<0.001)$.

\subsection{Correlation among self-directed learning, major satisfaction and problem solving ability}

The results showed thatself-directed learning had a statistically significant correlation with major satisfaction $(\mathrm{r}=0.408, \mathrm{p}<0.001)$. Further, there were significant positive correlations between self-directed learning and problem solving ability $(r=0.734, \mathrm{p}<0.001)$. There were significant positive correlation between major satisfaction and problem solving ability $(\mathrm{r}=0.485, \mathrm{p}<0.001)$.

\section{Discussion}

This study is a descriptive analysis on the relationship and the factors that influence the nursing students' self-directed learning, major satisfaction, and problem solving abilities.

The subjects' average score on self-directed learning was calculated as 3.22 points on a scale of 5 points as maximum. It was lower than the score that was presented in a study involving nursing students, Kim [12], who scored 3.51 points. Furthermore, the resulted data were low in this study for the reason that the subjects were only second year nursing students. It is thought to be necessary for various programs to be developed so the students may improve on their self-directed learning as they progress in years.

The average score on problem-solving ability was determined to be 3.28 out of 5 . The score was lower than that of Bae [13] study conducted on nursing students, but higher than that of Park [14] 3.12 study. Therefore, it is thought an important study subject that diverse programs are developed and applied in order to promote problem-solving ability for each year level.

Major satisfaction score was 3.88 out of 5. It was higher than the scores in the studies of Jung [15]. It is thought as necessary for an educational program that can attract the students' interest in the major, improve the students' major satisfaction, and give them confidence as they progress in years to be developed and applied.

It appeared that the subjects self-directed learning, major satisfaction, and problem-solving ability are all significant positive correlation.

Based on the above results, the problem solving ability of nursing students was higher on subjects who had higher self-directed learning and major satisfaction. It is suggested that a study on an extracurricular program development and a nursing intervention program development is implemented and that the programs to be applied in the nursing programs.

\section{Conclusion}

This study is a survey research to determine the relationship that influences the nursing students self-directed learning, major satisfaction, and problem solving abilities. To accomplish the purpose, the questionnaires were given to 203 students who attending nursing major of two 4-year universities where located in G for one month from May 2016.

By the result of research, the nursing students' self-directed learning has a significant positive correlation with major satisfaction and problem solving abilities. The collected data were low in this study for the reason that the inquiries were only second year nursing 
students. It is thought that various programs are necessary to be developed self-directed learning ability as they progress in years.

The problem solving ability was significant positively correlated with self-directed learning, and major satisfaction. Nursing students belong in the late of adolescence. They lack experiences about various problematic situations, critical thinking, and problem solving abilities.

Major satisfaction showed significant positive correlation with self-directed learning and major satisfaction. It is thought that various programs are necessary to arouse interest about nursing for nursing students.

Based on the result of this study, it is considered that replication study is necessary to be developed extracurricular programs which is to enhance various problem-solving abilities about major and clinical training, and applied them to nursing students. It is expected to contribute to improve nursing students' self-directed learning, major satisfaction, and problem solving abilities.

\section{References}

[1] H. J. Choi and E. J. Lee, "Mediation effects of self-efficacy between academic stress and college adjustment in first year nursing students," The Korean journal of fundamentals of nursing, vol.19, no.2, (2012)

[2] G. S. Jeong, K. A. Kim, and J. A. Seong, "The effect of learning style and critical thinking disposition on communication skill in nursing students," Journal of Korean academic Society of Nursing Education, vol.19, no.3, (2013)

[3] Y. K. Kim, "The effect of creative problem solving program on leadership, creativity and creativity problem solving of nursing students," Ph.D. dissertation, Cheonnam National University, Gwangju, Korea, (2009)

[4] Arnold. E, "Caring from the graduate student perspective," Journal of Hum Caring, vol.1, (1997)

[5] Knowles M. S, "Self-directed learning: A guide for learners and teachers," NY, Association Press, (1975) DOI: 10.3928/0022-0124-19760501-17

[6] I. S. Park and D. K. Kim, "Effect of TBL (Team-Based Learning) on oral prophylaxis education of dental hygiene curriculum," The Journal of Korean Academic Dental Health, vol.33, no.1, (2009)

[7] J. E. Brophy, "Synthesis of research on strategies for motivation student to learn," Educational Leadership, vol.45, no.3, (1987) DOI: 10.1111/j.1467-8535.1987.tb00656.x

[8] S. J. Lee, Y.K. Chang, and H. N. Park, "A study on the development of life-skills: communication, problem solving, and self-directed learning," Korean Educational Development Institute, Seoul, (2003)

[9] L. A. Braskamp, S. L. Wise, and D. D. Hengstler, "Student satisfaction as a measure of developmental quality,” Journal of Educational Psychology, vol.71, no.4, (1979) DOI: 10.1037/0022-0663.71.4.494

[10] K. H. Kim and H. S. Ha, "A study of department satisfaction factors of undergraduate students," The Korean Journal for Counseling, vol.1, no.1, (2000)

[11] S. J. Lee, Y.K. Chang, H. N. Lee, and G. Y. Park, “A study on the development of life-skills: communication, problem solving, and self-directed learning," Korean Educational Development Institute, Seoul, (2003)

[12] M. Y. Kim, "Affecting factors on clinical competence of nursing students," Journal of Korea AcademiaIndustrial cooperation Society, vol.16, no.3, (2015)

[13] Y. J. Bae and S. Y. Park, "Study on predictors of academic resilience in nursing students, The Journal of Korea Academia-Industrial cooperation Society," vol.15, no.3, (2014)

[14] Y. S. Park and Y. H. Kwon, "Ego resilience, problem solving process and clinical practice competency in nursing students," The Journal of Korean Academic Society of Nursing Education, vol.19, no.3, (2013)

[15] J. S. Jung, J. M. Jo, and Y. L. Young, "Relations between satisfaction in major, career decision-making selfefficacy and career identity of nursing students," The Journal of Academic Society Nursing Education, vol.20, no.1, (2014) 
A Study on the Relationship among Self-Direction Learning, Major Satisfaction and Problem-Solving Ability in Nursing Students

This page is empty by intention. 